\section{Tempers fray as production nears}

AN international row over hepatitis-B vaccine erupted last week, and rebounded badly on the French producer, Institut Pasteur Production (IPP).

To begin with, the French accused the World Health Organization (WHO) of being partisan, favouring a US vaccine over the French. WHO officials vehemently denied the accusation, describing it as a "smoke-screen" to deflect criticism from IPP and saying that IPP "broke its promise" to its customers (and WHO) by using undeclared (American) sources of plasma in the manufacture of its vaccine (see Nature 14 July, p.104).

WHO says there has been "silence" from France over IPP's production and testing methods, whereas the US producer (Merck, Sharp and Dohme) has provided full details of protocols, clinical studies and tests done by the independent Center for Disease Control at Atlanta. Although IPP has now promised full details, and although the French vaccine is probably at least as safe as the American, the whole

\section{Biogen's inside track}

\section{The Hague}

EFFICIENCY, safety and cheapness are the main advantages of Biogen's new hepatitisB vaccine, according to Dr Kenneth Murray's presentation of his findings here last week. The antigen is the result of six years of research in which the partners have been Biogen, the Dutch technological research organization TNO and Dr Murray's unit at the University of Edinburgh.

The Biogen vaccine is an antigen made from the gene for hepatitis-B surface antigen. Dr Murray explained last week that after experiments had shown that the gene could not be expressed in Escherichia coli, the team incorporated a sequence simulating the real gene in yeast.

The material is still on trial, but Dr Walter Gilbert, Biogen's chairman, announced last week that two chimpanzees had been successfully immunized against hepatitis $B$ using an experimental vaccine made from surface antigens produced by genetically engineered yeast. Two other chimpanzees, which did not receive the vaccine, contracted the disease after all four animals had been exposed to it. Blood tests confirmed that the chimpanzees receiving the Biogen vaccine were immune.

Biogen hopes to begin tests with its vaccine in human volunteers at the end of this year and hopes for official certification by 1984 or 1985 . The potential of the new product is considerable, not least in its relative cheapness. Last week, people were guessing that a dose of Biogen vaccine will cost $\$ 10$, compared with an estimated $\$ 100$ for the Merck and Institut Pasteur Production vaccines.

Geert Linnebank episode reflects badly on the company.

There may also be commercial consequences. WHO sets general criteria governing any new vaccine to be exported from one country to another. The criteria governing production standards and so on are not mandatory, but 130 of the 160 or so member states are poor countries with little or no capacity to set their own standards and which rely on WHO criteria. It is then up to companies marketing vaccines to declare whether their vaccines meet WHO criteria unless a member state asks for advice on a particular vaccine. No country has yet done this for the French hepatitis-B vaccine.

If IPP has cause for complaint, it may be that it was not involved early enough in the setting up of the WHO guidelines for hepatitis-B vaccine, so the guidelines - first established in 1979 - were better attuned to the Merck process than to the French. Merck, says WHO, was the only company in 1979 consistently producing acceptable vaccine ("ten batches out of ten") which had also submitted the vaccine to independent tests. Plainly it rankles in France, where the present vaccine was originally devised, that Merck had stolen such a march by 1979 . But IPP will have a hand, with other producers, in producing the third version of the guidelines due by December.

IPP's "broken promise" seems to centre on an undertaking not to use blood plasma containing the possibly infectious $E$ antigen of hepatitis-B virus (HB-E). Although WHO advisers had not insisted on this requirement, fearing that too little plasma would then be available, IPP's use of US plasma originally unscreened for HB-E and perhaps even found to be contaminated has invalidated the producer's claim to purity, a question on which the scare over acquired immune deficiency syndrome (AIDS) has made WHO especially sensitive.

Meanwhile, however, the fuss may be overtaken by events. The Swiss-based company Biogen has succeeded in producing test quantities of hepatitis-B vaccine from antigen genes cloned in yeast, and at least one other company is hard on its heels. According to Professor K. Murray of the University of Edinburgh, a Biogen adviser who cloned the original gene, human clinical trials may take place by the end of the year.

The technical problem of scale-up "would not be the limiting factor" said Murray but, rather, the time it took for the vaccine to satisfy national regulations for new vaccines. It could be on the market in two years, he said, as a product with no risk of contamination by AIDS or any other infectious agent. "It's an interesting reversal of the fears about genetic engineering of a few years ago" said Murray. Robert Walgate
Electron accelerators

\section{Argonne concedes defeat \\ Washington}

THE wrangle between Argonne National Laboratory and a consortium of southeastern universities over the right to build a proposed new electron accelerator ended abruptly last week with Argonne bowing out of the fight. Saying that stalemate could result in delay or outright cancellation of the project, Argonne director Walter Massey asked the Illinois congressional delegation to call off its effort to overturn the recommendation of an expert advisory committee in favour of the southeastern group.

The following day, the Department of Energy announced that the proposal from the Southeastern Universities Research Association (SURA) had been officially adopted and would be a candidate for the department's budget request for fiscal year 1985.

Argonne's decision to contest the recommendation of the Nuclear Science Advisory Committee (see Nature 7 July, p.7) went against a long tradition of respecting such decisions as the final word of the physics community. Many physicists expressed concern that Argonne's action threatened to drag the system of peer review on technical merits down to the level of pork-barrel politics.

White House science adviser George Keyworth expressed similar concern to Energy Secretary Donald Hodel and to Massey, and was the source of the scarcely veiled threat that if the dispute continued, the simplest solution might be to scrap the project altogether.

Massey said that while the loss of the project was a setback, Argonne would remain "one of the premier laboratories in nuclear physics" on the strength of its ATLAS heavy-ion accelerator, to be completed next year. Argonne has also already proposed another project on the scale of the electron accelerator, an advanced neutron source that would build on the laboratory's experience with its recently-completed Intense Pulsed Neutron Source. A letter to Massey from Illinois Senator Charles Percy last week mentioned continued efforts on the part of the congressional delegation to "locate new projects at the laboratory that equal or exceed the benefits to you and the region that were represented by the accelerator".

If all goes according to plan, and if Congress approves, construction of the 4-GeV accelerator will begin in October 1984, the beginning of the 1985 fiscal year. SURA is requesting \$4-5 million in operating funds for fiscal year 1984 in order to hire a core staff of 35-40 accelerator physicists, engineers and managers and to start essential prototype work.

Stephen Budiansky 